\title{
Colistin for lung infection: an update
}

\author{
Mohan Gurjar
}

\begin{abstract}
Increasing incidence of resistance of gram-negative bacteria against even newer antibiotic including carbapenem has generated interest in the old antibiotic colistin, which are being used as salvage therapy in the treatment of multidrug resistant infection. Colistin has excellent bactericidal activity against most gram-negative bacilli. It has shown persist level in the liver, kidney, heart, and muscle; while it is poorly distributed to the bones, cerebrospinal fluid, lung parenchyma, and pleural cavity. Being an old drug, colistin was never gone through the drug development process needed for compliance with competent regulatory authorities that resulted in very much limited understanding of pharmacokinetic (PK) and pharmacodynamic (PD) parameters, such as $C_{\text {max }} / \mathrm{MIC}$ ratio, AUC/MIC and T> MIC that could predict the efficacy of colistin. In available PK/PD studies of colistin, mean maximum serum concentration ( $\left.C_{\max }\right)$ of colistin were found just above the MIC breakpoint at steady states that would most probably lead to suboptimal for killing the bacteria, even at dosages of 3.0 million international units (MIU) i.e., $240 \mathrm{mg}$ of colistimethate sodium (CMS) intravenously every $8 \mathrm{~h}$. These finding stresses to use high loading as well as high maintenance dose of intravenous colistin. It is not only suboptimal plasma concentration of colistin but also poor lung tissue concentration, which has been demonstrated in recent studies, poses major concern in using intravenous colistin. Combination therapy mainly with carbapenems shows synergistic effect. In recent studies, inhaled colistin has been found promising in treatment of lung infection due to MDR gram-negative bacteria. New evidence shows less toxicity than previously reported.
\end{abstract}

Keywords: Colistin, Lung infection, Pneumonia, Ventilator-associated pneumonia, Critically ill

\section{Introduction}

Worldwide, there are growing threats to modern medicine from the emergence of multidrug resistant (MDR) bacteria causing nosocomial infection. This coupled with marked decline in the discovery and development of novel antibiotics especially against gram-negative bacteria in the last two decades leads to critical challenge to clinicians. MDR bacteria are usually defined as when it is resistant to three or more group of antibiotics. In clinical practice, antibiotics commonly used in treating gram-negative infection are penicillin, cephalosporin, carbapenem, monobactem, quinolone, and aminoglycoside. Increasing incidence of resistance of gram-negative bacteria against even newer antibiotic including carbapenem has been reported in many countries. In the last few years, with a paucity of available antibiotic option, interest has been renewed in the old antibiotic, polymyxins, as salvage therapy in the management of infections caused by MDR gram-negative

Correspondence: m.gurjar@rediffmail.com

Department of Critical Care Medicine, Sanjay Gandhi Postgraduate Institute of Medical Sciences (SGPGIMS), Lucknow, UP, India pathogens including Pseudomonas, Acinetobacter, Klebsiella, and Enterobacter species [1-3].

Polymyxins are group of cationic polypeptide antibiotics, having five different compounds (polymyxin A-E) [4]. In 1949, colistin (Polymyxin E) was first time isolated from Bacillus polymyxa var. colistinus by Koyama Y. and colleagues in Japan (Table 1) [5]. Only polymyxin E (Colistin) and polymyxin $B$ have been used in clinical practice since their discovery $[1,2]$. Both, colistin and polymyxib $B$, are produced by the soil bacterium Bacillus spp., and they differ in structure only by one amino acid at position 6 (-Leu in colistin, while -Phe in polymyxin B) [4].

Clinical experience is more with colistin in comparison to polymyxin B due to its wider use. After introduction in clinical practice, uses of parenteral colistin were gradually waned worldwide within two decades due to reported severe toxicities, while its topical uses continued [2-4]. So, era of colistin as intravenous use could be divided in three phases: 1950-1970: against gram-negative infection; 1990-2000: for MDR gram-negative pathogens in cystic fibrosis; and 2000 onwards: nosocomial infection due to MDR gram-negative pathogens. In this presented 
Table 1 History of colistin

\begin{tabular}{ll}
\hline Year & Event \\
\hline 1947 & $\begin{array}{l}\text { Discovery of polymyxins from bacteria Paenibacillus } \\
\text { polymyxa }\end{array}$ \\
& $\begin{array}{l}\text { Colistin (polymyxin E) was first time isolated from } \\
\text { Bacillus polymyxa var. colistinus by Koyama Y. and } \\
\text { colleagues in Japan }\end{array}$ \\
& $\begin{array}{l}\text { Colistin became available in intravenous formulation } \\
\text { (as colistimethate sodium) for clinical uses }\end{array}$ \\
& $\begin{array}{l}\text { Colistin used for gram-negative infection; later on, } \\
\text { uses decline due to its toxicities }\end{array}$ \\
& $\begin{array}{l}\text { Used mainly for lung infection due to MDR } \\
\text { gram-negative pathogens in patients with cystic } \\
\text { fibrosis }\end{array}$ \\
& $\begin{array}{l}\text { Currently in use to treat healthcare-associated MDR } \\
\text { gram-negative infection }\end{array}$ \\
\hline
\end{tabular}

descriptive review, we looked in published literature for the use of colistin in lung infection in critically ill patients without cystic fibrosis.

\section{Review}

\section{Current issues in colistin therapy}

Colistin, itself is composed of mixture of closely related components, mainly colistin A (polymyxin E1) and colistin B (polymyxin E2), which are acylated by (S)-6-methyloctanoic acid and (S)-6-methylheptanoic acid, respectively (Figure 1) [4]. Each molecule has a cationic polypeptide ring with a lipophilic fatty acid chain.

\section{Spectrum of activity}

Colistin has excellent bactericidal activity against most gram-negative bacilli, while no activity against all grampositive and most anaerobes (except few like Prevotella spp., Fusobacterium spp.) organisms (Table 2) [6]. Colistin has also been reported to be potentially active against several Mycobacterium spp. [7].

\section{Mechanism of action and resistance}

The targets site for colistin is lipopolysaccharide (LPS) component of the outer membrane of gram-negative bacteria. In there, colistin interacts with the lipid A component of the LPS, displacing the calcium and magnesium bridges that stabilize the LPS, leading to permeabilizing the bacterial outer membrane that can be described as detergent-like mechanism of action [4]. Subsequently, colistin inserted through these cracks in the outer membrane of bacteria causes 'self-promoted uptake' as well as disruption of the integrity of the inner membrane also that leads to bacterial killing $[1,4]$.

By another postulated mechanism, polycationic polymyxin binds to anionic phospholipid; this contact promotes lipid exchange between inner and outer membrane results in the loss of phospholipid composition leading to an osmotic imbalance resulting in lytic cell death [4].

The majority of mechanisms of resistance to colistin are based on modifications to the lipid A portion of LPS of gram-negative bacteria, like Pseudomonas aeruginosa and Escherichia coli, that reduces its net negative charge

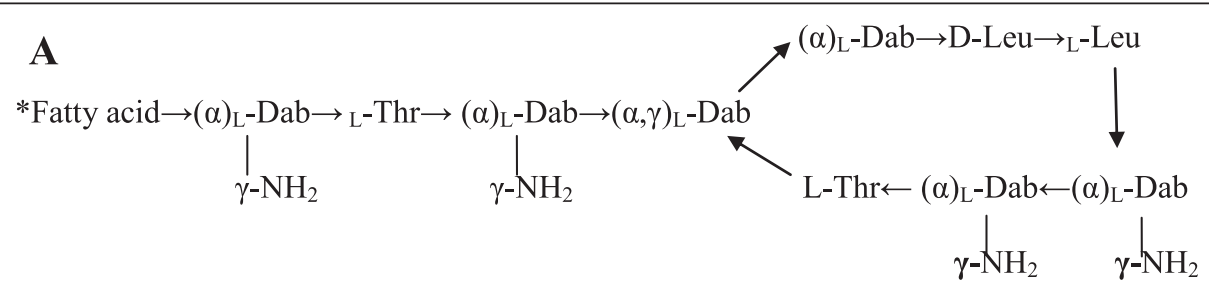

B

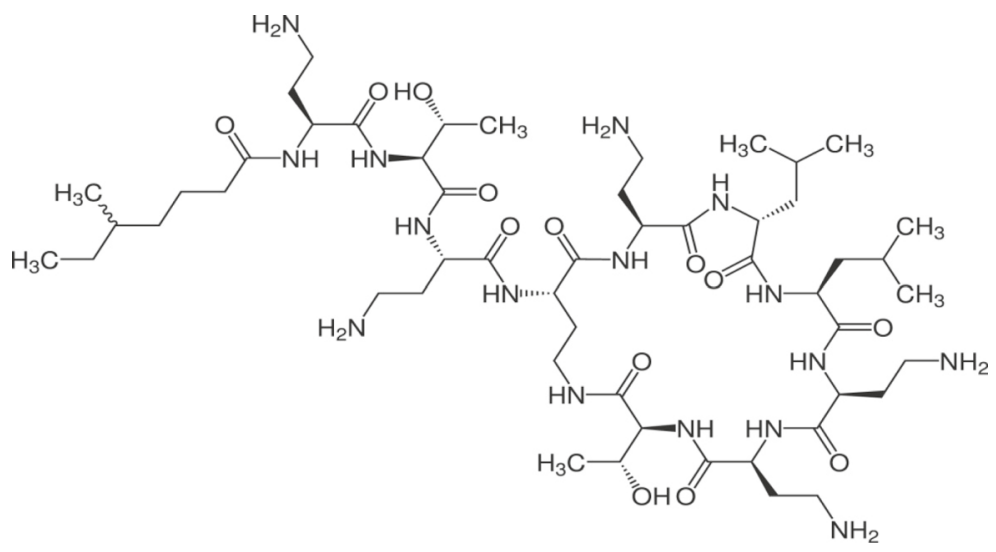

Figure 1 Descriptive and chemical structure of colistin. (A) Descriptive structure of colistin [*Fatty acid: (S)-6-methyloctanoic acid for colistin A, (S)-6-methylheptanoic acid for colistin B; Thr threonine, Leu leucine, Dab a,y-diaminobutyric acid]. (B) Chemical structure of colistin. 
Table 2 Spectrum of activity of colistin

\begin{tabular}{ll}
\hline Gram-negative bacteria & \\
\hline Susceptible & Resistant \\
\hline Gram-negative bacilli: Pseudomonas aeruginosa, & Gram-negative bacilli: Proteus spp., Providencic \\
Acinetobacter spp., Escherichia coli, Klebsiella spp., & spp., Morganella morgani, Serratia spp., Edwardsie \\
$\begin{array}{l}\text { Enterobacter spp., Citrobacter spp., Salmonella spp., } \\
\text { Shigella spp., Haemophilus influenza, Bordetella }\end{array}$ & tarda, Burkholderia spp., Brucella spp. \\
pertusis, Legionella pneumophila & \\
& \\
& Gram-negative cocci: Neisseria gonorrheae, \\
& Neisseria meningitides, Moraxella catarrhalis
\end{tabular}

resulting in less electrostatic interaction with positively charged colistin molecule [1,4]. While in Klebsiella pneumoniae, the mechanism of resistance to colistin is because of increased production of capsule polysaccharide [8].

\section{Susceptibility test and heteroresistance}

Antimicrobial susceptibility testing for colistin can be performed using either diffusion (disc diffusion, prediffusion test, or epsilometer test (E-test) or dilution techniques (broth microdilution or agar dilution) [6]. Colistin sulfate is recommended in susceptibility testing instead of colistimethate sodium (CMS) [2,6]. The reason for not using CMS in susceptibility testing, which is used clinically (see below), is an inactive pro-drug and also undergo variable hydrolysis resulting in differential killing characteristics and varying susceptibility report. There is another issue that colistin has, that because of its large molecule, it diffuses inadequately into the medium which makes disc diffusion test as a poor performer in susceptibility test. Among all these methods, broth microdilution and agar dilution methods are considered as reference methods $[6,9]$. Alternatively, E-test method is a reliable, easy to perform, and less time-consuming [6].

The breakpoints for colistin susceptibility are defined differently by two main societies: as per US Clinical and Laboratory Standards Institution (CLSI), $\leq 2 \mathrm{mg} / \mathrm{L}$ as the susceptibility breakpoint and $>2 \mathrm{mg} / \mathrm{L}$ as the resistance breakpoint, while as per British Society for Antimicrobial Chemotherapy (BSAC), $\leq 4 \mathrm{mg} / \mathrm{L}$ as susceptible and $\geq 8 \mathrm{mg} / \mathrm{L}$ as resistant [2].
In a population analysis, profiles of 'colistin-susceptible' clinical isolates Acinetobacter baumannii showed that subpopulation $<0.1 \%$ bacteria grew in the presence of colistin 3 to $10 \mu \mathrm{g} / \mathrm{ml}$, where minimum inhibitory concentration (MIC) of colistin against all isolates were within 0.25 to $2 \mu \mathrm{g} / \mathrm{ml}$ [10]. This represents the heterogeneous colistin-resistant in colistin-susceptible clinical isolates called 'heteroresistance'. This heteroresistance is observed more frequently in MDR A. baumannii and less in MDR P. aeruginosa. This heteroresistance phenomenon explains the substantial regrowth of $A$. baumannii occurring at $24 \mathrm{~h}$ even at colistin concentrations up to $64 \times$ MIC [10]. This heteroresistance also suggests that colistin monotherapy and extended interval dosage regimens may be problematic especially during treatment of A. baumannii.

\section{Commercially available forms}

Commercially, there are two available forms of colistin (Table 3): colistin sulfate for oral and topical use and CMS for parenteral use, as it is less toxic than colistin sulfate [1-3].

Colistimethate sodium, available as dry powder for reconstitution before administration, is marketed differently with respect to the content in the vial as well as recommended dose. Few brands (Colomycin, Coly-Monas, Xylistin) labeled the content as international unit, IU, (0.5, 1, or 2 million international units (MIU) per vial), while other (Coly-Mycin M) labeled the content as mg of colistin base activity (150 $\mathrm{mg}$ per vial) [2]. So, the clinician and

Table 3 Comparison of two different salts of colistin

\begin{tabular}{lll}
\hline & Colistimethate sodium & Colistin sulfate \\
\hline Prepared from & Colistin (chemically modified) & Synthesized non-ribosomally from Bacillus polymyxa subspecies colistinus \\
Salt & Sodium & Sulfate \\
Chemically & Polyanion & Polycation \\
Stability & Less & More \\
Elimination & Renal & Non-renal \\
Half-life & $\sim 2 \mathrm{~h}$ & $\sim 4 \mathrm{~h}$ \\
Anti-microbial activity & Non-active prodrug: 32 different products & Active \\
Available for & Parenteral use, inhalation use & Oral and topical use, inhalation use \\
\hline
\end{tabular}


researcher should be well aware about this product discrepancy as regards to dose content per vial by different brands, and prescription/description should be very much clear about dose as mg or IU of either CMS or colistin base activity.

Colistin activity equivalent

$1 \mathrm{mg}$ of $\mathrm{CMS}=0.375 \mathrm{mg}$ of colistin base activity = $12,500 \mathrm{IU}$

$1 \mathrm{mg}$ of colistin base activity $=2.6 \mathrm{mg}$ of $\mathrm{CMS}=$ $32,500 \mathrm{IU}$

\section{Pharmacokinetic/pharmacodynamic and optimal dosing of intravenous colistin}

CMS as not being stable both in vivo and vitro is hydrolysed to many derivatives including colistin and also makes it difficult to measure accurately both CMS and colistin in biological samples [2]. Available literature till now are not much clear about pharmacokinetics of colistin, especially in patient with various degrees of renal impairment [11]. Absorption from oral mucosa or gastrointestinal tract does not occur. After parenteral administration, colistin achieves low protein binding, approximately $50 \%$. About two thirds of CMS is eliminated as unchanged mainly by the renal route within $24 \mathrm{~h}[1,2]$. On the other hand, elimination of colistin is non-renal and non-biliary route by unknown mechanism $[2,11]$. It has shown persist level in the liver, kidney, heart, and muscle, while it is poorly distributed to the bones, cerebrospinal fluid, lung parenchyma, and pleural cavity $[1-3,11]$.

In most of the published literature, intravenous colistin were used in doses of 2.5 to $5.0 \mathrm{mg} / \mathrm{kg} /$ day in two to four divided doses in patients with normal renal function and also without clear mentioning of drug used in $\mathrm{mg}$ of either CMS or colistin base activity. Being an old drug, colistin was never gone through the drug development process needed for compliance with competent regulatory authorities that resulted in very much limited understanding of PK and PD parameters, such as $C_{\max } / \mathrm{MIC}$ ratio, AUC/MIC, and T > MIC that could predict the efficacy of colistin [2,11]. Recent studies started to reveal about $\mathrm{PK} / \mathrm{PD}$ of colistin and also demonstrate that it has poor postantibiotic effect (PAE) [11].

In PK/PD studies of colistin, mean maximum serum concentration $\left(C_{\max }\right)$ of colistin were found just above the MIC breakpoint of $2 \mathrm{mg} / \mathrm{L}$ (Clinical and Laboratory Standards Institute) at steady states that would most probably lead to suboptimal for killing the bacteria, even at dosages of $3.0 \mathrm{MIU}$ i.e., $240 \mathrm{mg}$ of CMS intravenously every $8 \mathrm{~h}$ [12-14]. Steady state concentration was achieved at least after $48 \mathrm{~h}$ of starting the intravenous colistin [12]. In a population of critically ill patients where pharmacokinetic analysis of colistin was done after intravenous administration, Plachouras et al. predicted that plasma colistin concentration on the basis of the model developed for different dosage regimen revealed that loading dose of 9 or 12 MIU of CMS as infusion of $15 \mathrm{~min}$ or $2 \mathrm{~h}$ with maintenance dose of $4.5 \mathrm{MIU}$ CMS every $12 \mathrm{~h}$ achieves rapid $(<12 \mathrm{~h})$ and higher plasma colistin in comparison to dosing regimen $3 \mathrm{MIU}$ as a 15min infusion of CMS every $8 \mathrm{~h}$, where it takes about $48 \mathrm{~h}$ to reach $2 \mathrm{mg} / \mathrm{L}$ [14]. Daikos et al. also studied the three different daily doses of CMS ( 3 MIU every 8 h, 4.5 MIU every $12 \mathrm{~h}$, and 9 MIU every $24 \mathrm{~h}$ ) that achieved mean serum concentration $\left(C_{\max }\right)$ of colistin $3.34,2.98$, and $5.63 \mu \mathrm{g} / \mathrm{ml}$, respectively, and found that all serum samples containing colistin $>4 \mu \mathrm{g} / \mathrm{ml}$ killed $P$. aeruginosa, whereas only $40 \%$ of samples containing colistin $<4 \mu \mathrm{g} / \mathrm{ml}$ results in complete eradication of $P$. aeruginosa (having MIC $1 \mu \mathrm{g} / \mathrm{ml}$ ) [13]. But at present, studies evaluating clinical outcome with these high dosage of colistin are lacking.

In a recent study of PK/PD of colistin, 2 MIU every $8 \mathrm{~h}$, in critically ill patients, Karnik ND et al. observed that the mean (range) of the maximum plasma drug concentration/minimum inhibitory concentration $\left(C_{\max } / \mathrm{MIC}\right)$ ratio for Acinetobacter spp. was $26.3(0.9-64.9)$ at steady state, while for Pseudomonas spp., it was 3.82 (2.3-10.9) [15]. This shows that an optimum value of the $C_{\max } / \mathrm{MIC}$ ratio of $>8$ was achieved against Acinetobacter, not for Pseudomonas. Bergen et al. examined the PK/PD relationship of colistin against $P$. aeruginosa and found that colistin efficacy against $P$. aeruginosa was best correlated with the AUC/MIC ratio of total and unbound colistin rather than the $C_{\max } / \mathrm{MIC}$ ratio [16].

It is not only the optimal plasma concentration but the site of infection also defines the optimal antimicrobial therapy. Interestingly, in a study, Imberti et al. found undetectable level of colistin in broncho-alveolar lavage fluid of critically ill patients at steady state mean plasma colistin maximum concentration of $2.21 \mu \mathrm{g} / \mathrm{ml}$ after the intravenous administration of CMS 2 MIU every $8 \mathrm{~h}$ for at least 2 days [17].

\section{Use in patients with renal dysfunction}

Despite colistin is eliminated by non-renal route, dose adjustment for renal dysfunction is necessary, as there is reduced renal dependent elimination of its pro-drug CMS which ultimately lead to increased colistin level $[2,11]$. Despite scarcity of studies of PK/PD of colistin in patients with renal failure, recent recommended doses are [2]:

Serum creatinine level 1.3-1.5 mg/dl: 2 MIU (160 mg) of CMS every $8 \mathrm{~h}$

Serum creatinine level 1.6-2.5 mg/dl: 2 MIU (160 mg) of CMS every $12 \mathrm{~h}$

Serum creatinine level $\geq 2.6 \mathrm{mg} / \mathrm{dl}: 2 \mathrm{MIU}(160 \mathrm{mg}$ ) of CMS every $24 \mathrm{~h}$ 
Patient on renal replacement therapy:

2 MIU (160 mg) of CMS after each hemodialysis 2 MIU (160 mg) of CMS daily during peritoneal dialysis

In a study about pharmacokinetics of colistin in critically ill patients receiving continuous venovenous hemodiafiltration (CRRT), Karvanen $\mathrm{M}$ et al. suggested that dose regimen of 2 MIU CMS every $8 \mathrm{~h}$ is inadequate [18]. In another recently published study, Honore et al. postulate from their experience that patients undergoing CRRT may receive substantially higher doses of colistin, i.e., high loading dose followed by a maintenance dose of up to $4.5 \mathrm{MIU}$ every $8 \mathrm{~h}$ because the drug is continuously filtered and also significantly adsorbed in the bulk of the dialysis membrane [19].

\section{Inhaled colistin}

For aerosol inhalation purpose, both forms of colistin (colistin sulfate and CMS) could be used [2,3]. Colistin, in the same intravenous formulation, is dissolved in 4-6 $\mathrm{ml}$ of normal saline or sterile water to deliver through nebulizer, though this is not approved by the Food and Drug Administration (FDA) [20,21]. There are few studies on the PK of colistin after inhalation. Ratjen et al. evaluated the colistin pharmacokinetics postinhalation in patients with cystic fibrosis [22]. This study finds that a single dose of CMS (2 MIU) achieve significant higher drug concentration in the sputum even after $12 \mathrm{~h}$ with low level in serum and urine. In another experimental study done by $\mathrm{Lu}$ et al. where pneumonia caused by $P$. aeruginosa in piglets and CMS was administered either by nebulization every $12 \mathrm{~h}$ or intravenous every $8 \mathrm{~h}$, lung tissue concentration of colistin was measured [23]. Colistin was found undetected in the lung tissue after intravenous infusion, while after nebulization, peak lung tissue concentrations were significantly higher in the lung segments (more in mild pneumonia segments and less in severe pneumonia area, median 10.0 versus $1.2 \mu \mathrm{g} / \mathrm{g}$ ).

As per drug package insert information, the recommended doses of colistin when given by inhalation are as below [24]:

Body weight <40 kg: 0.5 MIU (40 mg) of CMS every $12 \mathrm{~h}$ Body weight $>40 \mathrm{~kg}: 1.0 \mathrm{MIU}(80 \mathrm{mg})$ of CMS every $12 \mathrm{~h}$ For recurrent or severe pulmonary infection: 2.0 MIU (160 mg) of CMS every $8 \mathrm{~h}$

Optimal inhalation therapy also requires consideration of several factors like the type of nebulizer, aerosol particle size, position of patient, severity of airway obstruction, etc. In a mechanically ventilated patient, there are factors more than this, i.e., artificial airway size, humidity, gas density, tidal volume, nebulization cycling during inspiration versus continuous, etc., which may affect drug delivery at the target site [25].

\section{Combined therapy with other antibiotics and synergism}

In clinical practice, colistin is frequently used as combination therapy, though there is scarcity of data that whether combination therapy is superior to monotherapy. One of the reasons for limited studies may be using this drug in treating MDR pathogens that deterred the clinician from providing colistin as a monotherapy. In a recent review by Petrosillo et al. on colistin monotherapy versus combination therapy in animal and clinical studies, they revealed that synergistic effect was detected in all the nine studies examining the combination of colistin and rifampicin, whereas carbapenems exhibited a synergistic effect in two out of three studies [26]. Colistin combined with tigecycline did not show good synergistic action [27]. Considerable synergy was found between levofloxacin and colistin in a recently published study [28]. Pankuch et al. studied time killing synergy with subinhibitory concentration of meropenem and colistin and found significant synergy against $A$. baumannii at 6,12 , and 24 h, while there was no significant synergy against $P$. aeruginosa at any point of time [29]. In another in vitro study by Souli et al., the combination of imipenem (irrespective of MIC) and colistin against $K$. pneumoniae showed synergistic activity against isolates susceptible either to both agents or to colistin, while rarely synergistic against non-colistin-susceptible strains [30]. A recently published study by Leu et al. showed that the synergy of imipenem and colistin against imipenem-non-susceptible multi-drug resistant $A$. baumannii was significantly better for the colistin concentration at $1 \mathrm{mg} / \mathrm{L}$ than that at $0.5 \mathrm{mg} / \mathrm{L}$ [31].

\section{Toxicity}

Two types of toxicity, namely, nephrotoxicity and neurotoxicity has been reported with the uses of colistin. A systematic review of the toxicity of polymyxin revealed that in the old literature, incidences of both toxicities were reported to be considerably high, while new evidence shows less toxicity than previously reported [32]. The observed nephrotoxicity was as high as $50 \%$ in old studies versus $15 \%-25 \%$ in recent studies, although the definition of nephrotoxicity was not standardized between the studies [32]. Renal toxicity of colistin has been described as dose dependent and may be partly due to their D-amino acid content and fatty acid component that leads to acute tubular necrosis. Renal toxicity from colistin has been found apparently less than the use of polymyxin B [32]. Age (more than 60 years) has also been found as a significant risk for colistin-induced nephrotoxicity [33]. The concurrent administration of 
nephrotoxic drugs, hypovolemia or shock, and severity of illness may increase the likelihood of development of acute kidney injury (AKI).

In a recent preliminary study on high-dose colistin (9 MIU twice-daily), administration in critically ill patients found that AKI developed during 18\% of treatment courses did not require renal replacement therapy (RRT) and subsided within 10 days from colistin discontinuation [34]. Also, there was no correlation between variations in serum creatinine level and daily and cumulative doses of colistin or duration of colistin treatment. In another study, Dewan et al. also reported AKI in $16 \%$ of patients in whom high dose, extended interval colistin (9 MIU stat followed by 4.5 MIU 12 hourly) was used, while no patient required RRT [35].

Overall incidence of neurotoxicity related to colistin use is less than the nephrotoxicity. Earlier studies reported paresthesias in about one forth of patients receiving colistin, with few case reports of neuromuscular blockade or apnea, while recent studies did not reported any significant neurotoxicity [32,36]. Neurotoxicity is also dose dependent and may be triggered by the presence of risk factors like the presence of hypoxia, co-administration of muscle relaxant, narcotics, sedatives, or steroids [32,37,38].

Colistin aerosol inhalation therapy is generally well tolerated with few reported side effects like throat irritation, cough, and bronchospasm, which may be because of the presence of excipients/preservatives [20].

\section{Colistin for lung infection and clinical outcome}

In the last decade, many studies published the use of colistin in the treatment of lung infection in patients without cystic fibrosis, with conflicting results. Most of the studies have population of adult ICU patients with MDR VAP, and types of study were single-arm (Table 4) [11,39-75]. In a systematic review and meta-regression to know the efficacy of colistin for the treatment of VAP, Florescu et al. analyzed 6 controlled studies (359 patients) and singlearm analysis from 14 studies (437 patients) [76]. Among the six two-arm studies (three prospective including one RCT and three retrospective studies), which were unblinded, the mean duration of intravenous colistin was 11.4 days at a mean dose of $252.5 \mathrm{mg} / 70 \mathrm{~kg} /$ day and aerosolized colistin was administered for a mean 9.25 days at a mean dose of $355 \mathrm{mg} / 70 \mathrm{~kg} /$ day. While, in single-arm studies, intravenous colistin was used for a mean of 15 days at a mean dose of $209.5 \mathrm{mg} / 70 \mathrm{~kg} /$ day and aerosolized form was given for a mean of 14 days at a mean dose of $80 \mathrm{mg} / 70 \mathrm{~kg} /$ day. In the meta-analysis of six controlled studies, there was no significant difference for overall clinical response between colistin and control groups (OR 1.14 [95\% CI 0.74-1.77; $p=0.56$ ]; $I 2=0 \%$; $Q=4.98[p=0.42])$, even after controlling for concomitant antibiotic treatment, or for the dose of intravenous colistin. Though, there was a trend for better microbiological response. Also, there was no significant difference between the colistin and control groups with respect to ICU, hospital, or 28-day mortality. Neither, incidence of nephrotoxicity was different in both groups; but one study reported higher incidence for respiratory toxicity [55]. In the meta-analysis of single-arm studies, there was favorable clinical response with colistin found $(95 \% \mathrm{CI}$ $0.64-0.80 ; Q=55.3 ; p<0.0001)$. Also, there was a significant microbiological response for aerosolized form, but not with intravenous form. There was a higher incidence of nephrotoxicity with intravenous administration, and no patient had neurotoxicity or respiratory side effects. These single-arm studies also showed mortality benefit (ICU, hospital, as well as 28 -day mortality) in this meta-analysis [76].

In another recently published systematic review and meta-analysis of colistin for the treatment of VAP caused by MDR gram-negative bacteria, $\mathrm{Gu}$ et al. included 14 studies (published during 2003 to 2013, total 1,167 patients), 2 were RCTs, 4 were case-control studies, and 8 were cohort studies [77]. In this analysis for use of colistin versus $\beta$-lactam antibiotics, they found that there was no significant difference in both groups for clinical cure rate $(\mathrm{OR}=1,95 \% \mathrm{CI} 0.68-1.47, p=0.99, I 2=0 \%)$, microbiological eradication, ICU mortality, hospital mortality, and nephrotoxicity. While comparing aerosolized plus intravenous colistin (AS plus IV colistin) versus intravenous colistin alone, this meta-analysis revealed that AS plus IV colistin had a higher clinical cure rate $(\mathrm{OR}=2.12$, 95\% CI $1.40-3.20, p=0.0004, I 2=0 \%)$, but there was no significant differences in microbiological eradication, ICU, and hospital mortality and nephrotoxicity between both (AS plus IV colistin and intravenous colistin alone) groups. This meta-analysis also found that colistin-combined therapy did not have a better clinical cure, microbilogical eradication, ICU and hospital mortality, or nephrotoxicity, when compared with colistin monotherapy, for the treatment of MDR gram-negative VAP [77].

While another systematic review and meta-analysis on the role of aerosolized colistin in the treatment of VAP, Valachis et al. included 8 studies (690 patients) and found a statistically significant improvement in clinical response as well as microbiological eradication, when AS colistin was added to the standard antimicrobial therapy in comparison with patients who received IV colistin (OR, 1.57; 95\% CI, 1.14-2.15; $p=0.006$ and OR, 1.61; 95\% CI, 1.11-2.35; $p=0.01$, respectively) [78]. Overall mortality was not found to be significantly different between the two comparative arms (OR, 0.74; 95\% CI, 0.54-1.01; $\mathrm{p}=0.06)$. When AS colistin monotherapy was compared with IV colistin (31 patients, 2 studies), there was no differences between the two treatment arms for 
Table 4 Recent studies on colistin for the treatment of ventilator-associated pneumonia (VAP)

\begin{tabular}{|c|c|c|c|c|c|c|c|}
\hline Year & $\begin{array}{l}\text { Prospective or } \\
\text { retrospective }\end{array}$ & $\begin{array}{l}\text { Randomized } \\
\text { controlled trial }\end{array}$ & $\begin{array}{l}\text { Studied patients } \\
\text { with VAP }\end{array}$ & Organism isolated & $\begin{array}{l}\text { Route of } \\
\text { administration }\end{array}$ & Country & $\begin{array}{l}\text { First author } \\
\text { [reference] }\end{array}$ \\
\hline 2003 & Prospective & No & 35 & Acinetobacter baumanii & IV & Spain & Garnacho-Montero [39] \\
\hline 2003 & Prospective & No & 18 & Pseudomonas aeruginosa & IV & USA & Linden [40] \\
\hline 2003 & Prospective & No & 15 & $P$. aeruginosa, $A$. baumanii & IV & Greece & Markou [41] \\
\hline 2006 & Prospective & No & 9 & $P$. aeruginosa, $A$. baumanii & IV and AS & Greece & Falagas [42] \\
\hline 2006 & Prospective & No & 16 & A. baumanii & AS & Morocco & Motaouakkil [43] \\
\hline 2007 & Retrospective & No & 120 & $P$. aeruginosa, $A$. baumanii & IV & Tunisia & Kallel [44] \\
\hline 2007 & Retrospective & No & 61 & $P$. aeruginosa, $A$. baumanii & IV & Argentina & Rios [45] \\
\hline 2008 & Prospective & Yes & 28 & A. baumanii & IV & Greece & Betrosian [46] \\
\hline 2008 & Retrospective & No & 10 & A. baumanii & IV & Korea & Song [47] \\
\hline 2008 & Prospective & No & 8 & P. aeruginosa & IV and AS & Greece & Mastoraki [48] \\
\hline 2008 & Prospective & No & 19 & A. baumanii & IV & Italy & Bassetti [49] \\
\hline 2008 & Prospective & No & 60 & P. aeruginosa, A. baumanii, Klebseilla pneumoniae & AS & Greece & Michalopoulos [50] \\
\hline 2008 & Prospective & No & 10 & $P$. aeruginosa, $A$. baumanii & IV & Greece & Markou [11] \\
\hline 2009 & Retrospective & No & 9 & $P$. aeruginosa, $A$. baumanii & IV & Turkey & Tasbakan [51] \\
\hline 2009 & Retrospective & No & 41 & A. baumanii & IV & South Korea & Jang [52] \\
\hline 2010 & Retrospective & No & 86 & P. aeruginosa, A. baumanii, K. pneumoniae & IV and AS & Greece & Kofteridis [53] \\
\hline 2010 & Retrospective & No & 121 & P. aeruginosa, A. baumanii, K. pneumoniae & IV and AS & Greece & Korbila [54] \\
\hline 2010 & Prospective & Yes & 100 & P. aeruginosa, A. baumanii, K. pneumonia, Escherichia coli & AS & Thailand & Rattanaumpawan [55] \\
\hline 2010 & Retrospective & No & 45 & A. baumanii & AS & Taiwan & Lin [56] \\
\hline 2010 & Retrospective & No & 11 & P. aeruginosa, A. baumanii, K. pneumonia, Enterobacter cloacae & IV & Greece & losifidis [57] \\
\hline 2011 & Retrospective & No & 15 & A. baumanii & AS & Thailand & Nakwan [58] \\
\hline 2011 & Prospective & No & 15 & A. baumanii & IV and AS & Spain & Perez-Pedrero [59] \\
\hline 2011 & Retrospective & No & 20 & P. aeruginosa & IV and AS & Belgium & Naesena [60] \\
\hline 2012 & Prospective & No & 165 & $P$. aeruginosa, $A$. baumanii & AS & France & Lu [61] \\
\hline 2012 & Retrospective & No & 36 & A. baumanii & IV & Turkey & Simsek [62] \\
\hline 2012 & Retrospective & No & 45 & A. baumanii & IV and AS & Turkey & Kalin [63] \\
\hline 2013 & Retrospective & No & 98 & A. baumanii & IV & Israel & Zalts [64] \\
\hline 2013 & Retrospective & No & 208 & P. aeruginosa, A. baumanii, K. pneumonia & IV and AS & Italy & Tumbarello [65] \\
\hline 2013 & Prospective & Yes & 43 & A. baumanii & IV & Turkey & Aydemir [66] \\
\hline 2013 & Retrospective & No & 95 & $P$. aeruginosa, $A$. baumanii, K. pneumonia & IV and AS & USA & Doshi [67] \\
\hline 2013 & Retrospective & No & 49 & A. baumanii & IV and AS & Spain & Garnacho-Montero [68] \\
\hline 2014 & Retrospective & No & 82 & A. baumanii & IV & Turkey & Kalin [69] \\
\hline
\end{tabular}


Table 4 Recent studies on colistin for the treatment of ventilator-associated pneumonia (VAP) (Continued)

\begin{tabular}{|c|c|c|c|c|c|c|c|}
\hline 2014 & Retrospective & No & 26 & A. baumanii & AS & Taiwan & Hsieh [70] \\
\hline 2014 & Retrospective & No & 130 & A. baumanii & IV & Thailand & Khawcharoenporn [71] \\
\hline 2014 & Retrospective & No & 118 & A. baumanii & IV & Taiwan & Chuang [72] \\
\hline 2014 & Retrospective & No & 141 & A. baumanii, $P$. aeruginosa Enterobacteriaceae & IV & France & Soubirou [73] \\
\hline 2014 & Retrospective & No & 10 & A. baumanii & AS & Korea & Choi [74] \\
\hline 2014 & Retrospective & No & 107 & $P$. aeruginosa, $A$. baumanii & IV & Italy & Petrosillo [75] \\
\hline
\end{tabular}

IV intravenous, $A S$ aerosolized. 
clinical and microbiological eradication. The authors have also commented that the quality of evidences for the outcomes was very low according to the Grading of Recommendations Assessment, Development, and Evaluation (GRADE) approach [78].

All three meta-analyses of colistin for the treatment of VAP are summarized in Table 5.

\section{Future roadmap for optimization of the clinical use of colistin-'1st International Conference on Polymyxins,' Prato, Italy, 2013}

With the aim of better understanding of the current use of polymyxins, including factors affecting the safe and effective use of them, and identify research areas to fill gaps in existing knowledge, delegates from 27 countries from various specialties attended 'The 1st International Conference on Polymyxins' held in Prato, Italy, on 2-4 May, 2013. The consensus panel members identify highpriority issues, some of them are as follows [79]:

- Uniformity in expression of the amount of drug in a parenteral vial by different manufacturers should be expressed as mg of colistin base activity (CBA) or number of International Unit (IU)

- Uncertainties regarding susceptibility testing and breakpoints (currently under review jointly by the Clinical and Laboratory Standards Institute, CLSI and the European Committee on Antimicrobial Susceptibility Testing, EUCAST)
- Need of therapeutic drug monitoring in routine clinical practice (to maximize bacterial killing and minimize side effects in individual patients)

- Suggested research areas are prospective studies using therapeutic drug monitoring, pharmacokinetic studies in special patient populations, combination versus monotherapy, aerosol drug delivery alone, or in combination with intravenous route for the treatment of pneumonia

\section{Conclusions}

In recent time, the uses of colistin to treat lung infection due to MDR gram-negative bacteria have been increased throughout the world, with little understanding of PK/PD of colistin. The usual dose of 3 MIU of colistin every $8 \mathrm{~h}$ intravenously achieves plasma colistin concentration just above the MIC level, and it took at least $48 \mathrm{~h}$ to reach the steady plasma colistin level. These finding stresses to use high loading (9 or $12 \mathrm{MIU}$ of CMS) as well as high maintenance dose (4.5 MIU every $12 \mathrm{~h}$ or 9 MIU of CMS every $24 \mathrm{~h}$ ) of intravenous colistin, but there is scarcity of clinical studies with these doses. Using colistin with carbapenems has been found to have a synergistic action, though there is no strong evidence for using colistin/carbapenem combination therapy. On the other side, having PAE and heteroresistance phenomenon, especially for Acinetobacter infection, small-interval doses regimens of colistin may have better efficacy and reduces the chance of development of resistant against colistin. Currently, available

Table 5 Summary of 3 meta-analysis of colistin for the treatment of ventilator-associated pneumonia

\begin{tabular}{|c|c|c|c|}
\hline \multirow[t]{2}{*}{ Meta-analysis } & \multicolumn{3}{|l|}{ Outcome } \\
\hline & Clinical cure & Microbiological eradication & ICU mortality \\
\hline \multicolumn{4}{|l|}{ A. Florescu et al. [76] } \\
\hline $\begin{array}{l}\text { Colistin versus control } \\
\text { group }\end{array}$ & $\begin{array}{l}\text { Not significant; } 6 \text { two-arm studies, } \\
359 \text { patients (OR } 1.14[95 \% \mathrm{Cl} 0.74-1.77 ; \\
p=0.56] ; 12=0 \% ; Q=4.98[p=0.42])\end{array}$ & $\begin{array}{l}\text { Not significant; } 2 \text { studies, } 128 \text { patients } \\
\text { (OR } 1.997[95 \% \mathrm{Cl} 0.97-4.12 ; p=0.06] \\
\text { I2=2.48\%; } Q=1.03[p=0.31])\end{array}$ & $\begin{array}{l}\text { Not significant; } 2 \text { studies, } 155 \text { patients } \\
\text { (OR } 1.27[95 \% \mathrm{Cl} 0.66-2.43 ; p=0.47] \\
\text { I } 2=0 \% ; Q=0.057[p=0.81])\end{array}$ \\
\hline Single-arm studies & $\begin{array}{l}\text { Significant; } 13 \text { studies, } 429 \text { patients } \\
(95 \% \mathrm{Cl} 0.64-0.80 ; Q=55.3 ; p<0.0001)\end{array}$ & $\begin{array}{l}\text { Significant; } 9 \text { studies, } 267 \text { patients }(95 \% \\
\text { Cl } 0.44-0.79 ; Q=121.56 ; p<0.0001)\end{array}$ & $\begin{array}{l}\text { Significant; } 5 \text { studies, } 257 \text { patients }(95 \% \\
\text { Cl } 0.15-0.42 ; Q=43.61 ; p<0.0001)\end{array}$ \\
\hline \multicolumn{4}{|l|}{ B. Gu et al. [77] } \\
\hline $\begin{array}{l}\text { Colistin versus } \beta \text {-Lactam } \\
\text { antibiotics }\end{array}$ & $\begin{array}{l}\text { Not significant; } 6 \text { studies, } 507 \text { patients } \\
(\mathrm{OR}=1,95 \% \mathrm{Cl} 0.68-1.47, p=0.99 \\
12=0 \%)\end{array}$ & $\begin{array}{l}\text { Not significant; } 3 \text { studies, } 91 \text { patients } \\
(\mathrm{OR}=0.64,95 \% \mathrm{Cl} 0.18-2.22, p=0.48 \\
12=38 \%)\end{array}$ & $\begin{array}{l}\text { Not significant; } 3 \text { studies, } 320 \text { patients; } \\
(\mathrm{OR}=1.02,95 \% \mathrm{Cl} 0.60-1.72, p=0.95 \\
12=0 \%)\end{array}$ \\
\hline $\begin{array}{l}\text { AS + IV colistin versus } \\
\text { IV colistin alone }\end{array}$ & $\begin{array}{l}\text { Significant; } 3 \text { studies, } 415 \text { patients } \\
(\mathrm{OR}=2.12,95 \% \mathrm{Cl} 1.40-3.20, p=0.0004 \\
12=0 \%)\end{array}$ & $\begin{array}{l}\text { Not significant; } 2 \text { studies, } 242 \text { patients } \\
(\mathrm{OR}=1.29,95 \% \mathrm{Cl} 0.63-2.63, p=0.48 \\
12=43 \%)\end{array}$ & $\begin{array}{l}\text { Not significant; } 3 \text { studies, } 415 \text { patients } \\
(\mathrm{OR}=0.75,95 \% \mathrm{Cl} 0.50-1.11, p=0.15 \\
12=0 \%)\end{array}$ \\
\hline $\begin{array}{l}\text { Colistin-combined therapy } \\
\text { versus colistin monotherapy }\end{array}$ & $\begin{array}{l}\text { Not significant; } 5 \text { studies, } 245 \text { patients } \\
(\mathrm{OR}=1.38,95 \% \mathrm{Cl} 0.81-2.33, p=0.23 \\
12=0 \%)\end{array}$ & $\begin{array}{l}\text { Not significant; } 4 \text { studies, } 212 \text { patients } \\
(\mathrm{OR}=1.49,95 \% \mathrm{Cl} 0.79-2.83, p=0.22 \\
12=0 \%)\end{array}$ & $\begin{array}{l}\text { Not significant; } 2 \text { studies, } 123 \text { patients } \\
(\mathrm{OR}=0.48,95 \% \mathrm{Cl} 0.22-1.03, p=0.06 \\
12=0 \%)\end{array}$ \\
\hline \multicolumn{4}{|l|}{ C. Valachis et al. [78] } \\
\hline $\begin{array}{l}\text { Adjunctive AS colistin } \\
\text { versus IV colistin }\end{array}$ & $\begin{array}{l}\text { Significant; } 8 \text { studies, } 690 \text { patients } \\
(\mathrm{OR}, 1.57 ; 95 \% \mathrm{Cl}, 1.14-2.15 ; p=0.006)\end{array}$ & $\begin{array}{l}\text { Significant; } 7 \text { studies, } 479 \text { patients } \\
(\mathrm{OR}, 1.61 ; 95 \% \mathrm{Cl}, 1.11-2.35 ; p=0.01)\end{array}$ & $\begin{array}{l}\text { Not significant; } 7 \text { studies, } 668 \text { patients } \\
(\mathrm{OR}, 0.74 ; 95 \% \mathrm{Cl}, 0.54-1.01 ; p=0.06)\end{array}$ \\
\hline $\begin{array}{l}\text { AS colistin monotherapy } \\
\text { versus IV colistin }\end{array}$ & Not significant; 2 studies, 31 patients & Not significant; 2 studies, 31 patients & - \\
\hline
\end{tabular}


evidences throw highlight that different doses and/or dose intervals may be required for different types of gram-negative infections and warrant further studies for better understanding about PK/PD of colistin and its clinical applications. It is not only suboptimal plasma concentration of colistin but also poor lung tissue concentration, which has been demonstrated in recent studies, poses major concern in using intravenous colistin. Inhaled colistin as an adjunct treatment for lung infection due to MDR gram-negative bacteria have been found promising in recent studies as well as in meta-analysis.

\section{Competing interests}

The author declares that he has no competing interests.

\section{Acknowledgements}

Dr. Nirvik Pal and Dr. Gaurav Srivastava were acknowledged for their support in searching the articles.

Received: 31 October 2014 Accepted: 9 January 2015

Published online: 22 January 2015

\section{References}

1. Nation RL, Li J. Colistin in the 21st century. Curr Opin Infect Dis. 2009;22:535-43.

2. Li J, Nation RL, Turnidge JD, Milne RW, Coulthard K, Rayner CR, et al. Colistin: the re-emerging antibiotic for multidrug-resistant Gram-negative bacterial infections. Lancet Infect Dis. 2006;6:589-601.

3. Michalopoulos A, Falagas ME. Colistin and polymyxin B in critical care. Crit Care Clin. 2008;24:377-91.

4. Velkov T, Thompson PE, Nation RL, Li J. Structure-activity relationships of polymyxin antibiotics. J Med Chem. 2010;53:1898-916.

5. Koyama Y, Kurosawa A, Tsuchiya A, Takemuta K. A new antibiotic 'colistin' produced by spore-forming soil bacteria. J Antibiot (Tokyo). 1950;3:457-8.

6. Balaji V, Jeremiah SS, Baliga PR. Polymyxins: antimicrobial susceptibility concerns and therapeutic options. Indian J Med Microbiol. 2011;29:230-42.

7. Gupta S, Govil D, Kakar PN, Prakash O, Arora D, Das S, et al. Colistin and polymyxin B: a re-emergence. Indian J Crit Care Med. 2009;13:49-53.

8. Campos MA, Vargas MA, Regueiro V, Llompart CM, Albertí S, Bengoechea JA. Capsule polysaccharide mediates bacterial resistance to antimicrobial peptides. Infect Immun. 2004;72:7107-14.

9. Gales $A C$, Reis $A O$, Jones RN. Contemporary assessment of antimicrobial susceptibility testing methods for polymyxin B and colistin: review of available interpretative criteria and quality control quidelines. J Clin Microbiol. 2001;39:183-90.

10. Li J, Rayner CR, Nation RL, Owen RJ, Spelman D, Tan KE, et al. Heteroresistance to colistin in multidrug-resistant Acinetobacter baumannii. Antimicrob Agents Chemother. 2006:50:2946-50.

11. Michalopoulos AS, Falagas ME. Colistin: recent data on pharmacodynamics properties and clinical efficacy in critically ill patients. Ann Intensive Care. 2011;1:30.

12. Markou N, Markantonis SL, Dimitrakis E, Panidis D, Boutzouka E, Karatzas S, et al. Colistin serum concentrations after intravenous administration in critically ill patients with serious multidrug-resistant, gram-negative bacilli infections: a prospective, open-label, uncontrolled study. Clin Ther. 2008;30:143-51.

13. Daikos GL, Skiada A, Pavleas J, Vafiadi C, Salatas K, Tofas P, et al. Serum bactericidal activity of three different dosing regimens of colistin with implications for optimum clinical use. J Chemother. 2010;22:175-8.

14. Plachouras D, Karvanen M, Friberg LE, Papadomichelakis E, Antoniadou A, Tsangaris I, et al. Population pharmacokinetic analysis of colistin methanesulfonate and colistin after intravenous administration in critically ill patients with infections caused by Gram-negative bacteria. Antimicrob Agents Chemother. 2009:53:3430-6.

15. Karnik ND, Sridharan K, Jadhav SP, Kadam PP, Naidu RK, Namjoshi RD, et al Pharmacokinetics of colistin in critically ill patients with multidrug-resistant Gram-negative bacilli infection. Eur J Clin Pharmacol. 2013;69:1429-36.
16. Bergen PJ, Bulitta JB, Forrest A, Tsuji BT, Li J, Nation RL. Pharmacokinetic/ pharmacodynamic investigation of colistin against Pseudomonas aeruginosa using an in vitro model. Antimicrob Agents Chemother. 2010;54:3783-9.

17. Imberti R, Cusato M, Villani P, Carnevale L, lotti GA, Langer M, et al. Steady-state pharmacokinetics and BAL concentration of colistin in critically III patients after IV colistin methanesulfonate administration. Chest. 2010;138:1333-9.

18. Karvanen $M$, Plachouras $D$, Friberg LE, Paramythiotou E, Papadomichelakis $E$, Karaiskos I, et al. Colistin methanesulfonate and colistin pharmacokinetics in critically ill patients receiving continuous venovenous hemodiafiltration. Antimicrob Agents Chemother. 2013;57:668-71.

19. Honoré PM, Jacobs R, Joannes-Boyau O, Lochy S, Boer W, De Waele E, et al. Continuous renal replacement therapy-related strategies to avoid colistin toxicity: a clinically orientated review. Blood Purif. 2014;37(4):291-5.

20. Antoniu SA, Cojocaru I. Inhaled colistin for lower respiratory tract infections. Expert Opin Drug Deliv. 2012;9:333-42.

21. Michalopoulos A, Papadakis E. Inhaled anti-infective agents: emphasis on colistin. Infection. 2010;38:81-8.

22. Ratjen F, Rietschel E, Kasel D, Schwiertz R, Starke K, Beier H, et al. Pharmacokinetics of inhaled colistin in patients with cystic fibrosis. J Antimicrob Chemother. 2006:57:306-11.

23. Lu Q, Girardi C, Zhang M, Bouhemad B, Louchahi K, Petitjean O, et al. Nebulized and intravenous colistin in experimental pneumonia caused by Pseudomonas aeruginosa. Intensive Care Med. 2010;36:1147-55.

24. Pharmax Ltd. Colomycin package insert information. In: Colomycin 1,000,000 IU vial-colistin sulphomethate sodium. Bexley: Pharmax Ltd; 1998. Bexley.

25. Dhand R, Guntur VP. How best to deliver aerosol medications to mechanically ventilated patients. Clin Chest Med. 2008;29:277-96.

26. Petrosillo N, loannidou E, Falagas ME. Colistin monotherapy vs. combination therapy: evidence from microbiological, animal and clinical studies. Clin Microbiol Infect. 2008;14:816-27.

27. Petersen PJ, Labthavikul P, Jones CH, Bradford PA. In vitro antibacterial activities of tigecycline in combination with other antimicrobial agents determined by chequerboard and time-kill kinetic analysis. J Antimicrob Chemother. 2006;57:573-6.

28. Safarika A, Galani I, Pistiki A, Giamarellos-Bourboulis EJ. Time-kill effect of levofloxacin on multidrug-resistant Pseudomonas aeruginosa and Acinetobacter baumannii: synergism with imipenem and colistin. Eur J Clin Microbiol Infect Dis. 2014 Sep 6. [Epub ahead of print]

29. Pankuch GA, Lin G, Seifert H, Appelbaum PC. Activity of meropenem with and without Ciprofloxacin and Colistin against Pseudomonas aeruginosa and Acinetobacter baumannii. Antimicrob Agents Chemother. 2008;52:333-6.

30. Souli M, Rekatsina PD, Chryssouli Z, Galani I, Giamarellou H, Kanellakopoulou K. Does the activity of the combination of imipenem and colistin in vitro exceed the problem of resistance in metallo-beta-lactamase-producing Klebsiella pneumoniae isolates? Antimicrob Agents Chemother. 2009;53:2133-5.

31. Leu HS, Ye JJ, Lee MH, Su LH, Huang PY, Wu TL, Huang CT. Synergy of imipenem/colistin methanesulfonate combinations against imipenemnonsusceptible multidrug-resistant Acinetobacter baumannii. J Microbiol Immunol Infect. 2013 Jul 5. doi:pii: S1684-1182(13)00086-8. 10.1016/j. jmii.2013.05.007. [Epub ahead of print].

32. Falagas ME, Kasiakou SK. Toxicity of polymyxins: a systematic review of the evidence from old and recent studies. Crit Care. 2006;10:R27.

33. Balkan II, Dogan M, Durdu B, Batirel A, Hakyemez IN, Cetin B, et al. Colistin nephrotoxicity increases with age. Scand J Infect Dis. 2014;46(10):678-85.

34. Dalfino L, Puntillo F, Mosca A, Monno R, Spada ML, Coppolecchia S, et al. High-dose, extended-interval colistin administration in critically ill patients: is this the right dosing strategy? A preliminary study. Clin Infect Dis. 2012;54:1720-6.

35. Dewan A, Shoukat M. Evaluation of risk of nephrotoxicity with high dose, extended-interval colistin administration. Indian J Crit Care Med. 2014;18(7):427-30

36. Koch-Weser J, Sidel W, Federman EB, Kanarek P, Finer DC, Eaton AE. Adverse effects of sodium colistimethate. Manifestations and specific reaction rates during 317 courses of therapy. Ann Intern Med. 1970;72:857-68.

37. Perkins RL. Apnea with intramuscular colistin therapy. JAMA. 1964;190:421-4.

38. de Gouw NE, Crul JF, Vandermeersch E, Mulier JP, van Egmond J, Van Aken $\mathrm{H}$. Interaction of antibiotics on pipecuronium-induced neuromuscular blockade. J Clin Anesth. 1993;5:212-5. 
39. Garnacho-Montero J, Ortiz-Leyba C, Jiménez-Jiménez FJ, Barrero-Almodóvar AE, García-Garmendia JL, Bernabeu-Wittell M, et al. Treatment of multidrugresistant Acinetobacter baumannii ventilator-associated pneumonia (VAP) with intravenous colistin: a comparison with imipenem-susceptible VAP. Clin Infect Dis. 2003;36(9):1111-8.

40. Linden PK, Kusne S, Coley K, Fontes P, Kramer DJ, Paterson D. Use of parenteral colistin for the treatment of serious infection due to antimicrobial-resistant Pseudomonas aeruginosa. Clin Infect Dis. 2003:37(11):e154-60.

41. Markou N, Apostolakos H, Koumoudiou C, Athanasiou M. Intravenous colistin in the treatment of sepsis from multiresistant Gram-negative bacilli in critically ill patients. Crit Care. 2003;7(5):R78-83.

42. Falagas ME, Kasiakou SK, Kofteridis DP, Roditakis G, Samonis G. Effectiveness and nephrotoxicity of intravenous colistin for treatment of patients with infections due to polymyxin-only-susceptible (POS) gram-negative bacteria. Eur J Clin Microbiol Infect Dis. 2006;25(9):596-9.

43. Motaouakkil S, Charra B, Hachimi A, Nejmi H, Benslama A, Elmdaghri N, et al. Colistin and rifampicin in the treatment of nosocomial infections from multiresistant Acinetobacter baumannii. J Infect. 2006;53(4):274-8.

44. Kallel H, Hergafi L, Bahloul M, Hakim A, Dammak H, Chelly H, et al. Safety and efficacy of colistin compared with imipenem in the treatment of ventilator-associated pneumonia: a matched case-control study. Intensive Care Med. 2007:33(7):1162-7.

45. Rios FG, Luna CM, Maskin B, Saenz Valiente A, Lloria M, Gando S, et al. Ventilator-associated pneumonia due to colistin susceptible-only microorganisms. Eur Respir J. 2007;30(2):307-13.

46. Betrosian AP, Frantzeskaki F, Xanthaki A, Douzinas EE. Efficacy and safety of high-dose ampicillin/sulbactam vs. colistin as monotherapy for the treatment of multidrug resistant Acinetobacter baumannii ventilator-associated pneumonia. J Infect. 2008:56(6):432-6.

47. Song JY, Lee J, Heo JY, Noh JY, Kim WJ, Cheong HJ, et al. Colistin and rifampicin combination in the treatment of ventilator-associated pneumonia caused by carbapenem-resistant Acinetobacter baumannii. Int J Antimicrob Agents. 2008;32(3):281-4.

48. Mastoraki A, Douka E, Kriaras I, Stravopodis G, Manoli H, Geroulanos S. Pseudomonas aeruginosa susceptible only to colistin in intensive care unit patients. Surg Infect (Larchmt). 2008;9(2):153-60.

49. Bassetti M, Repetto E, Righi E, Boni S, Diverio M, Molinari MP, et al. Colistin and rifampicin in the treatment of multidrug-resistant Acinetobacter baumannii infections. J Antimicrob Chemother. 2008;61(2):417-20.

50. Michalopoulos A, Fotakis D, Virtzili S, Vletsas C, Raftopoulou S, Mastora Z, et al. Aerosolized colistin as adjunctive treatment of ventilator-associated pneumonia due to multidrug-resistant Gram-negative bacteria: a prospective study. Respir Med. 2008;102(3):407-12.

51. Taşbakan MS, Pullukçu H, Ekren PK, Oz AT, Midilli M, Aydemir S, et al. Colistin use in ventilator-associated pneumonia due to panresistant Pseudomonas aeruginosa and Acinetobacter baumannii. Mikrobiyol Bul. 2009;43(1):61-70.

52. Jang HJ, Kim MN, Lee K, Hong SB, Lim CM, Koh Y. The comparative efficacy of colistin monotherapy and combination therapy based on in vitro antimicrobial synergy in ventilator-associated pneumonia caused by multi-drug resistant Acinetobacter baumannii. Tuberc Respir Dis; 2009;67(3):212-20.

53. Kofteridis DP, Alexopoulou C, Valachis A, Maraki S, Dimopoulou D, Georgopoulos D, et al. Aerosolized plus intravenous colistin versus intravenous colistin alone for the treatment of ventilator-associated pneumonia: a matched case-control study. Clin Infect Dis. 2010;51(11):1238-44.

54. Korbila IP, Michalopoulos A, Rafailidis PI, Nikita D, Samonis G, Falagas ME. Inhaled colistin as adjunctive therapy to intravenous colistin for the treatment of microbiologically documented ventilator-associated pneumonia: a comparative cohort study. Clin Microbiol Infect. 2010;16(8):1230-6.

55. Rattanaumpawan P, Lorsutthitham J, Ungprasert P, Angkasekwinai N, Thamlikitkul V. Randomized controlled trial of nebulized colistimethate sodium as adjunctive therapy of ventilator-associated pneumonia caused by Gram-negative bacteria. J Antimicrob Chemother. 2010;65(12):2645-9.

56. Lin CC, Liu TC, Kuo CF, Liu CP, Lee CM. Aerosolized colistin for the treatment of multidrug-resistant Acinetobacter baumannii pneumonia: experience in a tertiary care hospital in northern Taiwan. J Microbiol Immunol Infect. 2010:43(4):323-31.

57. Iosifidis E, Antachopoulos C, loannidou M, Mitroudi M, Sdougka M, Drossou-Agakidou V, et al. Colistin administration to pediatric and neonatal patients. Eur J Pediatr. 2010;169(7):867-74.
58. Nakwan N, Wannaro J, Thongmak T, Pornladnum P, Saksawad R, Nakwan N, et al. Safety in treatment of ventilator-associated pneumonia due to extensive drug-resistant Acinetobacter baumannii with aerosolized colistin in neonates: a preliminary report. Pediatr Pulmonol. 2011;46(1):60-6.

59. Pérez-Pedrero MJ, Sánchez-Casado M, Rodríguez-Villar S. Nebulized colistin treatment of multi-resistant Acinetobacter baumannii pulmonary infection in critical ill patients. Med Intensiva. 2011;35(4):226-31.

60. Naesens $R$, Vlieghe $E$, Verbrugghe $W$, Jorens $P$, leven $M$. A retrospective observational study on the efficacy of colistin by inhalation as compared to parenteral administration for the treatment of nosocomial pneumonia associated with multidrug-resistant Pseudomonas aeruginosa. BMC Infect Dis. 2011;11:317.

61. Lu Q, Luo R, Bodin L, Yang J, Zahr N, Aubry A, et al. Efficacy of high-dose nebulized colistin in ventilator-associated pneumonia caused by multidrug-resistant Pseudomonas aeruginosa and Acinetobacter baumannii. Anesthesiology. 2012;117(6):1335-47.

62. Simsek F, Gedik H, Yildirmak MT, Iris NE, Türkmen A, Ersoy A, et al. Colistin against colistin-only-susceptible Acinetobacter baumannii-related infections: monotherapy or combination therapy? Indian J Med Microbiol. 2012;30(4):448-52.

63. Kalin G, Alp E, Coskun R, Demiraslan H, Gündogan K, Doganay M. Use of high-dose IV and aerosolized colistin for the treatment of multidrug-resistant Acinetobacter baumannii ventilator-associated pneumonia: do we really need this treatment? J Infect Chemother. 2012;18(6):872-7.

64. Zalts R, Neuberger A, Hussein K, Raz-Pasteur A, Geffen Y, Mashiach T, Finkelstein R. Treatment of carbapenem-resistant Acinetobacter baumannii ventilator-associated pneumonia: retrospective comparison between intravenous colistin and intravenous ampicillin-sulbactam. Am J Ther. 2013 Nov 20. [Epub ahead of print]

65. Tumbarello M, De Pascale G, Trecarichi EM, De Martino S, Bello G, Maviglia R, et al. Effect of aerosolized colistin as adjunctive treatment on the outcomes of microbiologically documented ventilator-associated pneumonia caused by colistin-only susceptible gram-negative bacteria. Chest. 2013:144(6):1768-75.

66. Aydemir H, Akduman D, Piskin N, Comert F, Horuz E, Terzi A, et al. Colistin vs. the combination of colistin and rifampicin for the treatment of carbapenem-resistant Acinetobacter baumannii ventilator-associated pneumonia. Epidemiol Infect. 2013;141(6):1214-22.

67. Doshi NM, Cook CH, Mount KL, Stawicki SP, Frazee EN, Personett HA, et al. Adjunctive aerosolized colistin for multi-drug resistant gram-negative pneumonia in the critically ill: a retrospective study. BMC Anesthesiol. 2013;13(1):45.

68. Garnacho-Montero J, Amaya-Villar R, Gutiérrez-Pizarraya A, Espejo-Gutiérrez De Tena E, Artero-González ML, Corcia-Palomo Y, et al. Clinical efficacy and safety of the combination of colistin plus vancomycin for the treatment of severe infections caused by carbapenem-resistant Acinetobacter baumannii. Chemotherapy. 2013;59(3):225-31

69. Kalin G, Alp E, Akin A, Coskun R, Doganay M. Comparison of colistin and colistin/sulbactam for the treatment of multidrug resistant Acinetobacter baumannii ventilator-associated pneumonia. Infection. 2014;42(1):37-42.

70. Hsieh TC, Chen FL, OU TY, Jean SS, Lee WS. Role of aerosolized colistin methanesulfonate therapy for extensively-drug-resistant Acinetobacter baumannii complex pneumonia and airway colonization. J Microbiol Immunol Infect. 2014 Oct 31. pii: S1684-1182(14)00178-9. doi:10.1016/j. jmii.2014.08.009. [Epub ahead of print]

71. Khawcharoenporn T, Pruetpongpun N, Tiamsak P, Rutchanawech S, Mundy LM, Apisarnthanarak A. Colistin-based treatment for extensively drug-resistant Acinetobacter baumannii pneumonia. Int J Antimicrob Agents. 2014;43(4):378-82.

72. Chuang YC, Cheng CY, Sheng WH, Sun HY, Wang JT, Chen YC, et al. Effectiveness of tigecycline-based versus colistin-based therapy for treatment of pneumonia caused by multidrug-resistant Acinetobacter baumannii in a critical setting: a matched cohort analysis. BMC Infect Dis. 2014;14:102.

73. Soubirou JF, Gault N, Alfaiate T, Lolom I, Tubach F, Andremont A, et al. Ventilator-associated pneumonia due to carbapenem-resistant Gram-negative bacilli in an intensive care unit without carbapenemase-producing Enterobacteriaceae or epidemic Acinetobacter baumannii. Scand J Infect Dis. 2014;46(3):215-20.

74. Choi HK, Kim YK, Kim HY, Uh Y. Inhaled colistin for treatment of pneumonia due to colistin-only-susceptible Acinetobacter baumannii. Yonsei Med J. 2014;55(1):118-25. 
75. Petrosillo N, Giannella M, Antonelli M, Antonini M, Barsic B, Belancic L, et al. Clinical experience of colistin-glycopeptide combination in critically ill patients infected with Gram-negative bacteria. Antimicrob Agents Chemother. 2014;58(2):851-8.

76. Florescu DF, Qiu F, McCartan MA, Mindru C, Fey PD, Kalil AC. What is the efficacy and safety of colistin for the treatment of ventilator-associated pneumonia? A systematic review and meta-regression. Clin Infect Dis. 2012:54:670-80.

77. Gu WJ, Wang F, Tang L, Bakker J, Liu JC. Colistin for the treatment of ventilator-associated pneumonia caused by multidrug-resistant Gram-negative bacteria: a systematic review and meta-analysis. Int J Antimicrob Agents. 2014 Aug 10. pii: S0924-8579(14)00235-0. doi:10.1016/j.jjantimicag.2014.07.004. [Epub ahead of print]

78. Valachis A, Samonis G, Kofteridis DP. The role of aerosolized colistin in the treatment of ventilator-associated pneumonia: a systematic review and metaanalysis. Crit Care Med. 2014 Dec 9. [Epub ahead of print]

79. Nation RL, Li J, Cars O, Couet W, Dudley MN, Kaye KS, Mouton JW, Paterson DL, Tam VH, Theuretzbacher U, Tsuji BT, Turnidge JD. Framework for optimisation of the clinical use of colistin and polymyxin B: the Prato polymyxin consensus. Lancet Infect Dis. 2014 Oct 21. pii: S1473-3099(14) 70850-3. doi: 10.1016/S1473-3099(14)70850-3. [Epub ahead of print]

\section{Submit your next manuscript to BioMed Central and take full advantage of:}

- Convenient online submission

- Thorough peer review

- No space constraints or color figure charges

- Immediate publication on acceptance

- Inclusion in PubMed, CAS, Scopus and Google Scholar

- Research which is freely available for redistribution 